\title{
A case of corticobasal degeneration studied with positron emission tomography
}

\author{
H. Nagasawa' ${ }^{1}$, T. Imamura', H. Nomura', M. Itoh ${ }^{2}$ and T. Ido² \\ ${ }^{1}$ Department of Neurology, Institute of Brain Diseases, Tohoku University School of \\ Medicine, 1-1 Seiryo-machi, Aoba-ku, Sendai 980, and ${ }^{2}$ Cyclotron and Radioisotope \\ Center, Tohoku University, Aramaki Aoba, Aoba-ku, Sendai 980, Japan
}

Correspondence to: H. Nagasawa at above address

\begin{abstract}
We measured cerebral blood flow, oxygen metabolism, glucose utilization, and dopamine metabolism in the brain of a patient with corticobasal degeneration using positron emission tomography (PET). The clinical picture is distinctive, comprising features referable to both cortical and basal ganglionic dysfunction. Brain imagings of glucose and dopamine metabolism can demonstrate greater abnormalities in the cerebral cortex and in the striatum contralateral to the more affected side than those of blood flow and oxygen metabolism. This unique combination study measuring both cerebral glucose utilization and dopamine metabolism in the nigrostriatal system can provide efficient information about the dysfunctions which are correlated with individual clinical symptoms, and this study is essential to diagnosis of corticobasal degeneration.
\end{abstract}

Keywords: Cerebral blood flow - Corticobasal degeneration - Dopamine metabolism - Glucose metabolism - Magnetic resonance imaging - Oxygen metabolism - Positron emission tomography

\section{INTRODUCTION}

In 1968, Rebeiz et al. described the clinical and pathological findings in three patients with what they called "corticodentatonigral degeneration with neuronal achromasia". Thereafter, Gibb et al. (1989) reported three patients and reviewed the clinical and pathological features of corticobasal degeneration. The diagnosis of corticobasal degeneration can be predicted during life on the basis of clinical findings, but a definitive diagnosis requires confirmation by autopsy (Riley et al., 1990). However, a recent study using positron emission tomography (PET) indicated that distinctive supportive findings for the diagnosis could be obtained with this technique (Watts et al., 1985; Eidelberg et al., 1989; Sawle et al., 1991). In the present study, we measured cerebral blood flow (CBF), cerebral oxygen consumption $\left(\mathrm{CMRO}_{2}\right)$, cerebral glucose utilization (CMRGlc), and dopamine metabolism in a patient with corticobasal degeneration using PET.

\section{CASE AND METHODS}

\section{Case}

A 71-year-old right-handed man developed disturbances of mental activity, spontaneity, and change of personality in 1988. He then became unsteady and was unable to walk without assistance in 1989. On examination in March 1991 , he was alert and well oriented, and his mental status examination was normal. A neurologist noted generalized hyperreflexia, akinesia, limb rigidity and dystonia which were greater on the left, and prominent slowness and awkwardness of movements of the left hand. A left alien limb was also present with bilateral grasp reflexes. There was apraxia of the left hand with no sensory deficit and constructional disturbance of the right hand when copying figures. He complained of losing his balance and falling due to severe impairment of postural reflexes and his gait was markedly disturbed because of prominent apraxia.

\section{Positron emission tomography}

PET study was performed on a scanner, PT-931 (CTI Inc, USA), at the Cyclotron Radioisotope Center, Tohoku University, Sendai, Japan. This study was approved by the Research Ethics Committee of the Tohoku University, School of Medicine. The patient gave his written informed consent after a full explanation of the procedure.

For all studies, the patient was positioned in the scanner with the orbitomeatal (OM) line parallel to the detector rings. Using the bed and gantry coordinates, we tried to position the head in exactly the same position for each study. Before scanning, a short 21-gauge cannula was inserted to a brachial artery for arterial blood sampling. All the procedures were performed in a semidarkened room and the position of the patient enabled him only to see the ceiling of the scanner. A 15-min transmission scan was collected using a retractable germanium 68-gallium 68 
ring source. To determine $\mathrm{CBF}$ and $\mathrm{CMRO}_{2}$, steady-state emission data were collected for two scans each of $10 \mathrm{~min}$ duration, during inhalation of $\mathrm{C}^{15} \mathrm{O}_{2}$ and ${ }^{15} \mathrm{O}_{2}(370 \mathrm{MBq} /$ $\mathrm{min})$, respectively, with sufficient washout time following each study. Each scan was reconstructed into 14 planes with an $8 \mathrm{~mm}$ axial and transaxial resolution. Regional $\mathrm{CBF}$ and $\mathrm{CMRO}_{2}$ were calculated according to Frakowiak et al. (1980) from the emission scans using arterial oxygen content and whole blood and plasma radioactivity counts measured in triplicate during each scan. To determine CMRGlc, a series of three emission scans each of $10 \mathrm{~min}$ duration was commenced $30 \mathrm{~min}$ after an intravenous bolus injection of $185 \mathrm{MBq}(5 \mathrm{ml}) 2\left[{ }^{18} \mathrm{~F}\right]$-fluoro-2-deoxyD-glucose $\left({ }^{18} \mathrm{FDG}\right)$. Twenty blood samples were collected to determine the plasma radioactivities and glucose concentrations, taken every 10 min during the study (Hatazawa et al., 1988). Regional CMRGlc was calculated from the emission scans using plasma radioactivity counts and the operational equation derived by Phelps et al. (1979) and Huang et al. (1980) from Sokoloff et al. (1977). A total of 22 regions of interest (ROIs) were manually placed on the calculated images as determined by reference to magnetic resonance images (MRI) and neuroanatomical atlases (Salamon and Huang, 1980; Talairach and Tournoux, 1988).

On a separate occasion, dynamic emission scans, each of $5 \mathrm{~min}$ duration, were performed over $60 \mathrm{~min}$ after an intravenous bolus injection of $185 \mathrm{MBq}(5 \mathrm{ml})\left[{ }^{18} \mathrm{~F}\right]-6-$ fluorodopa (FDOPA) in order to assess the presynaptic functional integrity of the nigrostriatal system. Emission data were simultaneously collected from seven contiguous axial sections, each about $6 \mathrm{~mm}$ in thickness from $\mathrm{OM}+66$ to $\mathrm{OM}+22 \mathrm{~mm}$. After data collection, the latter six continuous images of the same brain slice scanned between 30 and $60 \mathrm{~min}$ after administration of FDOPA were added and composite images were obtained in order to improve the contrast between dopaminergic and nondopaminergic brain regions. FDOPA metabolism was determined using target-to-background ratio (TBR) values, which were the ratio of the accumulated activity in the caudate nucleus or the putamen to that in the ipsilateral cerebellum of each hemisphere as a reference area (Nagasawa, et al., 1993).

\section{RESULTS}

Representative appearances of brain images obtained by $\mathrm{MR}$ and those of $\mathrm{CMRGlc}, \mathrm{CBF}$, and $\mathrm{CMRO}_{2}$ are shown in Fig. 1. Regional $\mathrm{CBF}$ and $\mathrm{CMRO}_{2}$ were markedly decreased with no asymmetry in the bilateral supratentorial brain structures including the cerebral cortex, the thalamus, the caudate nucleus, and the putamen compared with the values of the cerebellum. On the other hand, the brain imagings of CMRGlc were quite different from

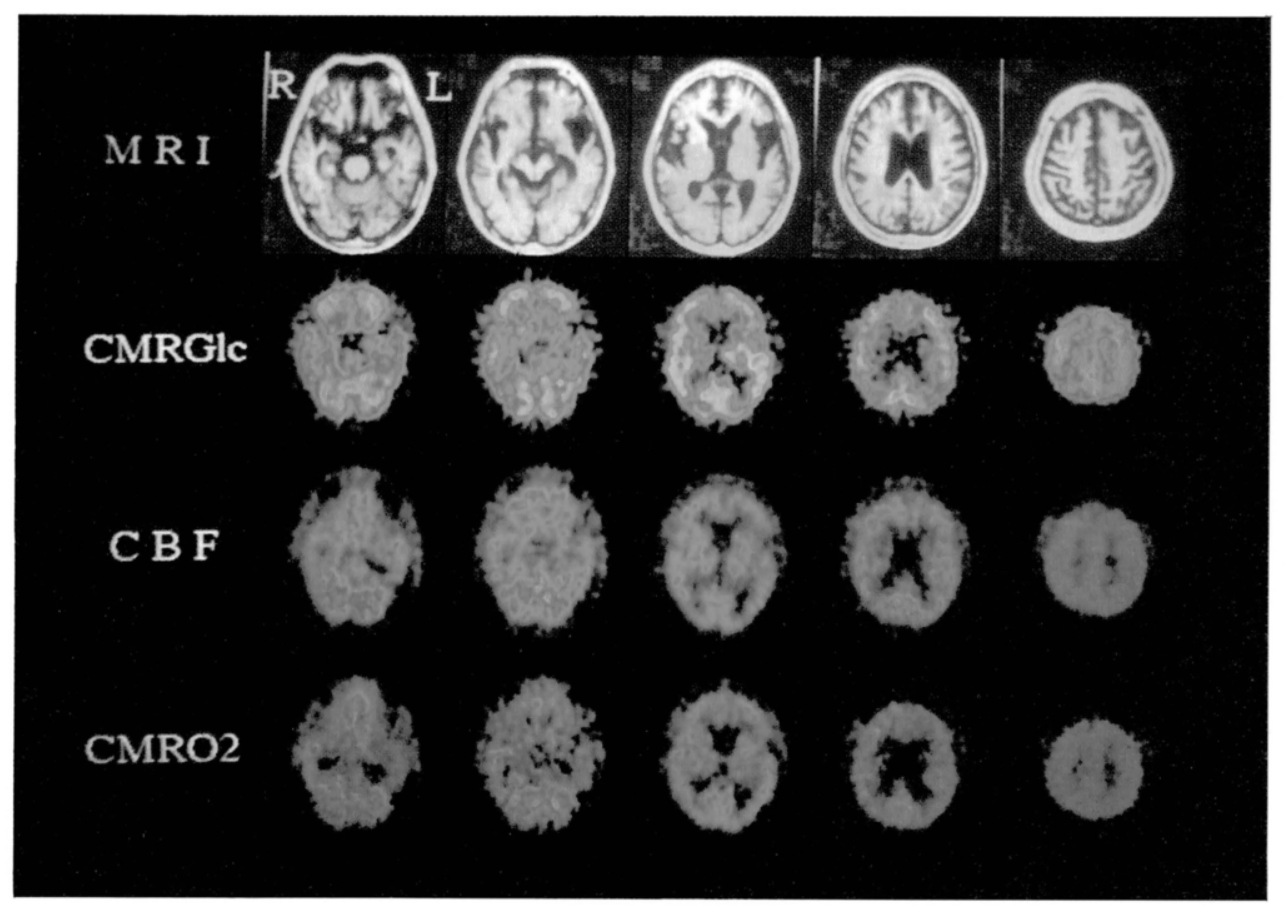

FIG. 1. Representative appearances of brain imagings obtained by magnetic resonance and those of cerebral metabolic rate of glucose (color scale ranged from 0 to $15 \mathrm{mg} / 100 \mathrm{~g} / \mathrm{min}$ ), cerebral blood flow (color scale ranged from 0 to $100 \mathrm{ml} / 100 \mathrm{~g} / \mathrm{min}$ ), and cerebral metabolic rate of oxygen (color scale ranged from 0 to $10 \mathrm{mg} / 100 \mathrm{~g} / \mathrm{min}$ ) in the same brain slices. 
TABLE I. Cerebral metabolic rate of glucose of normal control subjects and a patient with corticobasal degeneration

\begin{tabular}{lccc}
\hline Structure & Control & \multicolumn{2}{c}{ Patient } \\
\cline { 3 - 4 } & & $\begin{array}{c}\text { Right } \\
\text { hemisphere }\end{array}$ & $\begin{array}{c}\text { Left } \\
\text { hemisphere }\end{array}$ \\
\hline Frontal cortex & & & \\
Superior frontal cortex & & 8.03 & 9.23 \\
Medial frontal cortex & $8.67 \pm 0.66$ & 8.64 & 8.94 \\
Medial mesial frontal cortex & $8.63 \pm 0.97$ & 8.60 & 8.80 \\
Inferior frontal cortex & $8.53 \pm 1.10$ & 8.40 & 8.46 \\
Lateral frontal cortex & $8.72 \pm 1.31$ & 8.40 & 8.50 \\
Lateral posterior frontal cortex & $8.16 \pm 1.30$ & 7.60 & 7.50 \\
Parietal cortex & $8.23 \pm 0.92$ & & \\
Primary motor and sensory cortex & $9.17 \pm 0.77$ & 7.40 & 8.50 \\
Posterior parietal cortex & $8.64 \pm 0.51$ & 7.10 & 7.70 \\
Lateral parietal cortex & $8.66 \pm 1.20$ & 7.12 & 7.65 \\
Temporal cortex & & & \\
Superior temporal cortex & $8.70 \pm 0.88$ & 8.80 & 9.40 \\
Medial temporal cortex & $8.50 \pm 0.77$ & 8.16 & 7.60 \\
Inferior temporal cortex & $7.70 \pm 0.80$ & 7.37 & 7.53 \\
Temporal pole & $7.25 \pm 0.99$ & 7.10 & 7.50 \\
Occipital cortex & $8.35 \pm 0.84$ & 8.70 & 9.30 \\
Primary visual area & $9.51 \pm 0.88$ & 9.48 & 9.48 \\
Associative visual area & $9.45 \pm 1.11$ & 8.40 & 9.90 \\
Centrum semiovale & $7.34 \pm 0.68$ & 6.63 & 6.43 \\
Thalamus & $8.79 \pm 0.95$ & 7.65 & 9.45 \\
Caudate nucleus & $9.13 \pm 0.88$ & 8.16 & 7.60 \\
Putamen & $8.67 \pm 0.88$ & 7.63 & 9.23 \\
Brainstem & $7.06 \pm 0.46$ & 6.40 & 6.43 \\
Cerebellum & $7.70 \pm 1.23$ & 8.33 & 8.40 \\
\hline Control values are given & & &
\end{tabular}

Control values are given in $\mathrm{mg} / 100 \mathrm{~g} / \mathrm{min}$ (mean \pm S.D.) from six subjects.

those of $\mathrm{CBF}$ and $\mathrm{CMRO}_{2}$. The values of CMRGlc in each structure of the six normal control subjects and the patient are represented in Table I. The values of regional CMRGlc decreased in the parietal cortex, the thalamus and the putamen, this was more severe on the right side, and these findings were compatible with the asymmetric clinical features of the patient.

Brain CT and FDOPA PET brain slices of a normal subject at the level of the caudate nucleus and the putamen are shown in Fig. 2A. FDOPA and its metabolites were highly concentrated in the caudate nucleus and the putamen of both hemispheres. The values of TBR in the caudate nucleus and the putamen of 10 normal subjects were (mean \pm S.D.) $1.81 \pm 0.23$ and $1.92 \pm 0.28$, respectively. On the contrary, in the case of the patient, the mean values of TBR decreased to 1.52 in the caudate nucleus and 1.44 in the putamen, and were more reduced in the right hemisphere (Fig. 2B, C, Table II).

\section{DISCUSSION}

The clinical diagnosis of corticobasal degeneration was made in this case on the basis of an asymmetric akineticrigid syndrome with apraxia and an alien limb (Rebeiz et al., 1968; Gibb et al., 1989). MRI revealed no responsible lesion except for moderate atrophy of the bilateral frontal and parietal cortices. The most remarkable PET findings were a reduction of CMRGlc in the thalamus and the parietal region contralateral to the more affected side, and a reduction of FDOPA accumulation in both caudate nucleus and putamen. Glucose is the main substrate for cerebral metabolism and many studies have confirmed a correlation between physiological function and glucose metabolism in the central nervous system (Sokoloff, 1977). Therefore, measurement of cerebral glucose utilization can provide an index of brain functions. No significant findings with asymmetry in relationship to the clinical features were found by measuring $\mathrm{CBF}$ and $\mathrm{CMRO}_{2}$ in the present study. However, there are some reports about the usefulness of measurement of $\mathrm{CMRO}_{2}$ (Sawle et al., 1991) or CBF (Okuda et al., 1992) for the diagnosis of corticobasal degeneration. Okuda et al. (1992) reported that the regional CBF decreased in the unilateral frontal and parietal cortices by using a single photon emission computed tomography and that such findings were in agreement with asymmetric clinical symptoms of two patients with corticobasal degeneration. Further detailed investigations for more patients using PET are 

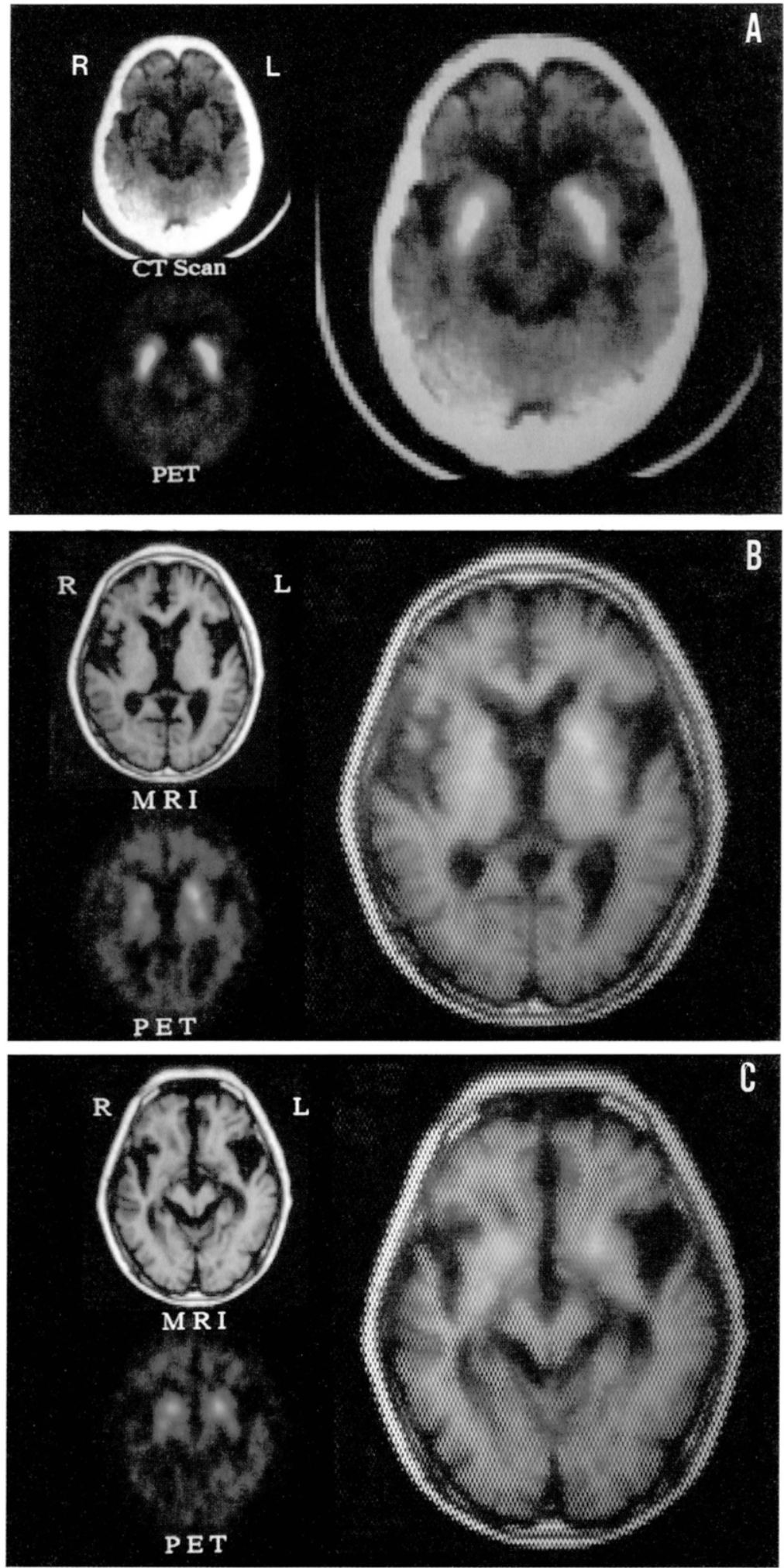

FIG. 2. Two different images obtained using $\left[{ }^{18} \mathrm{~F}\right]-6$-fluorodopa (FDOPA) positron emission tomography and computed tomography or magnetic resonance at the level of the caudate nucleus and the putamen from a normal control $(A)$ and from the patient with corticobasal degeneration (B, C). FDOPA accumulation was decreased in the caudate nucleus and the putamen. This decrease was more severe on the right side of the brain than the left. 
TABLE II. The values of target-to-background ratio of normal control subjects and a patient with corticobasal degeneration

\begin{tabular}{lcc}
\hline & Caudate/cerebellum & Putamen/cerebellum \\
\hline Corticobasal degeneration & & \\
Left side & 1.58 & 1.48 \\
Right side & 1.46 & 1.40 \\
Normal control $(n=10)$ & $1.81 \pm 0.23$ & $1.92 \pm 0.28$ \\
\hline
\end{tabular}

The mean values of target-to-background ratio of the patient were calculated using two brain slices as shown in Fig. 2B, C.

$n$, Number of subjects.

required for an analysis of $\mathrm{CBF}$ and metabolism in relation to the clinical symptoms of corticobasal degeneration.

The accumulation of FDOPA into striatum reflects its uptake into dopaminergic neurons, conversion into $\left[{ }^{18} \mathrm{~F}\right]$-dopamine by dopa decarboxylase, and storage in terminal neurotransmitter vesicles (Firnau et al., 1987). We have demonstrated that measurement of FDOPA metabolism with PET using FDOPA, combined with a new anatomical localization method to identify the caudate nucleus and the putamen on the overlapped images as shown in Fig. 2, can reveal specific abnormalities in patient with corticobasal degeneration (Nagasawa et al., 1993). FDOPA metabolism was estimated by using the values obtained as the individual ratio of FDOPA accumulation in the caudate nucleus and the putamen to those in the cerebellum. Reduced accumulation in the caudate nucleus and the putamen are considered to represent a reduction in the number of functioning nigrostriatal dopaminergic neurons (Leenders et al., 1986), and these findings in our case, which are more severe on the right side, reflect the left-sided predominance of the akinetic-rigid syndrome studied.

\section{CONCLUSION}

The most important PET findings were a reduction in FDOPA uptake in both caudate nuclei and putamina and thalamoparietal metabolic asymmetries; glucose metabolism was more reduced contralateral to the more affected side. The unique combination study measuring both cerebral glucose utilization and dopamine metabolism in the nigrostriatal system can provide further supportive evidence for the presumptive clinical diagnosis.

\section{Acknowledgements}

We thank Mr Shinya Seo and Mr Shoichi Watanuki for technical assistance.

\section{REFERENCES}

Eidelberg D, Moeller JR, Sidtis JJ, Dhawan V, Strother SC and Fahn S (1989) Corticodentatonigral degeneration: metabolic asymmetries studied with ${ }^{18} \mathrm{~F}$-fluorodeoxyglucose and posi- tron emission tomography. Neurology, Cleveland, 39, Supplement 1,164 .

Firnau G, Sood S, Chirakal R, Nahmias C and Garnett ES (1987) Cerebral metabolism of $6-\left[{ }^{18} \mathrm{~F}\right]$ fluoro-L-3, 4-dihydroxyphenylalanine in the primate. Journal of Neurochemistry, 48, 1077-1082.

Frackowiak RSJ, Lenzi GL, Jones T and Heather DJ (1980) Quantitative measurement of regional cerebral blood flow and oxygen metabolism in man using ${ }^{15} \mathrm{O}$ and positron emission tomography: theory, procedure, and normal values. Journal of Computer Assisted Tomography, 4, 727-736.

Gibb WRG, Luthert PJ and Marsden CD (1989) Corticobasal degeneration. Brain, 112, 1171-1192.

Hatazawa J, Itoh M, Matsuzawa T, Ido T and Watanuki S (1988) Measurement of the ratio of cerebral oxygen consumption to glucose utilization by positron emission tomography: its consistency with the values determined by the Kety-Schmidt method in normal volunteers. Journal of Cerebral Blood Flow and Metabolism, 8, 426-432.

Huang SC, Phelps ME, Hoffman EJ, Sideris K, Selin CJ and Kuhl DE (1980) Noninvasive determination of local cerebral metabolic rate of glucose in man. American Journal of Physiology, 238, E69-82.

Leenders KL, Palmer AJ, Quinn N, Clark JC, Firnau G, Garnett ES, Nahmias C, Jones T and Marsden CD (1986) Brain dopamine metabolism in patients with Parkinson's disease measured with positron emission tomography. Journal of Neurology, Neurosurgery, and Psychiatry, 49, 853-860.

Nagasawa H, Saito H, Kogure K, Hatazawa J, Itoh M, Fujiwara T, Watanuki S, Seo S, Iwata R and Ido T (1993) 6-[18F]Fluorodopa metabolism in patients with hemiparkinsonism studied by positron emission tomography. Journal of the Neurological Sciences, 115, 136-143.

Okuda B, Tachibana H, Kawabata K, Takeda M and Sugita M (1992) Slowly progressive limb-kinetic apraxia with a decrease in unilateral cerebral blood flow. Acta Neurologica Scandinavica, 86, 76-81.

Phelps ME, Huang SC, Hoffman EJ, Selin C, Sokoloff L and Kuhl DE (1979) Tomographic measurements local cerebral metabolic rate in humans with (F18)2-fluoro-2-deoxy-D-glucose: validation of method. Annals of Neurology, 6, 371-388.

Rebeiz JJ, Kolodny EH and Richardson EP (1968) Corticodentatonigral degeneration with neuronal achromasia. Archives of Neurology, Chicago, 18, 20-33.

Riley DE, Lang AE, Lewis A, Resch L, Ashby P, Hornykiewicz $O$ and Black S (1990) Cortico-basal ganglionic degeneration. Neurology, Cleveland, 40, 1203-1212.

Salamon G and Huang YP (1980) Computed Tomography of the Brain. Springer, Berlin.

Sawle GV, Brooks DJ, Marsden CD and Frackowiak RSJ (1991) Corticobasal degeneration. A unique pattern of regional corti- 
cal oxygen hypometabolism and striatal fluorodopa uptake demonstrated by positron emission tomography. Brain, 114, 541-556.

Sokoloff L (1977) Relation between physiological function and energy metabolism in the central nervous system. Journal of Neurochemistry, 29, 13-26.

Sokoloff L, Reivich M, Kennedy C, Des Rosiers MH, Patlak CS, Pettigrew KD, Sakurada O and Shinohara M (1977) The $\left[{ }^{14} \mathrm{C}\right]$ deoxyglucose method for the measurement of local cerebral glucose utilization: theory, procedure, and normal values in the conscious and anesthetized albino rat. Journal of Neurochemistry, 28, 897-916.
Talairach J and Tournoux P (1988) Co-planar Stereotaxic Atlas of the Human Brain. Three-dimensional Proportional System: an Approach to Cerebral Imaging. Thieme, Stuttgart.

Watts RL, Williams RS, Growdon JD, Young RR, Haley EC and Beal MF (1985) Corticobasal ganglionic degeneration. Neurology, Cleveland, 35, Supplement 1, 178.

(Received 25 January 1993; accepted 10 February 1993) 


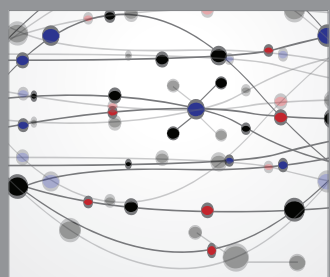

The Scientific World Journal
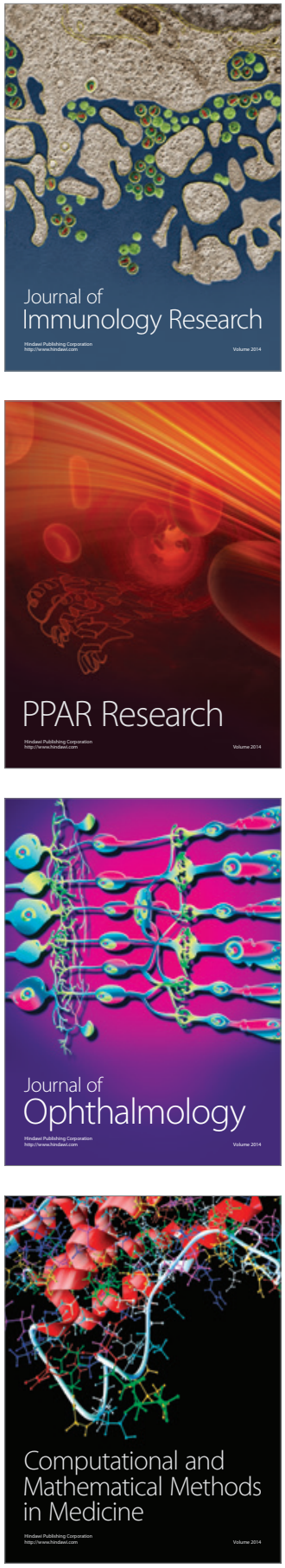

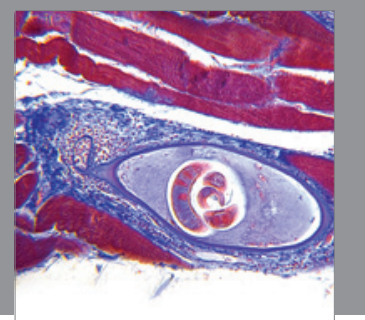

Gastroenterology

Research and Practice
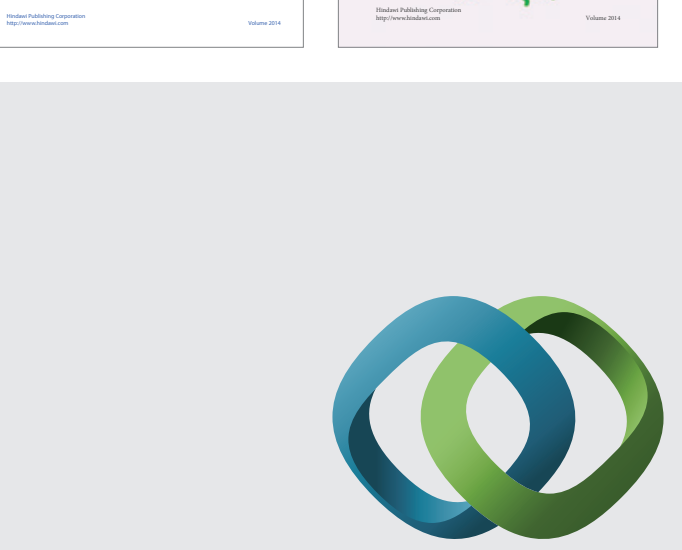

\section{Hindawi}

Submit your manuscripts at

http://www.hindawi.com
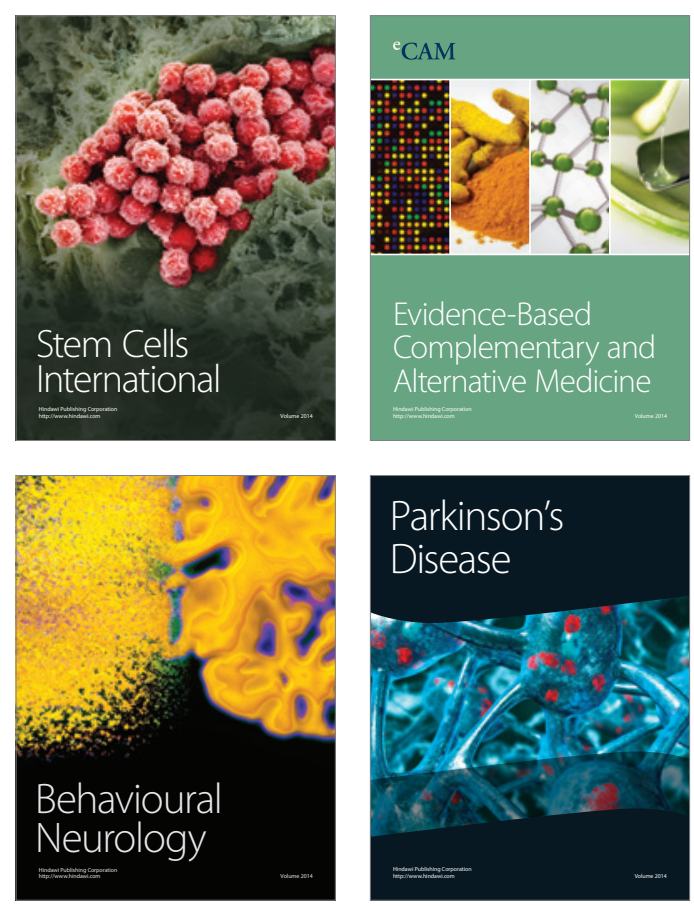

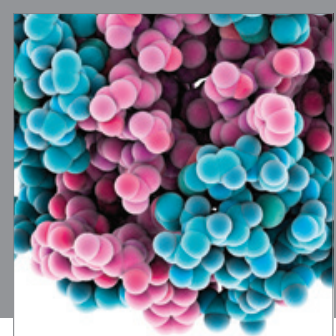

Journal of
Diabetes Research

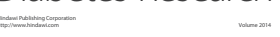

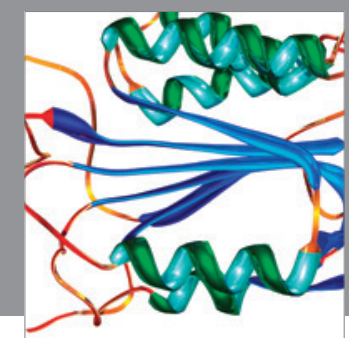

Disease Markers
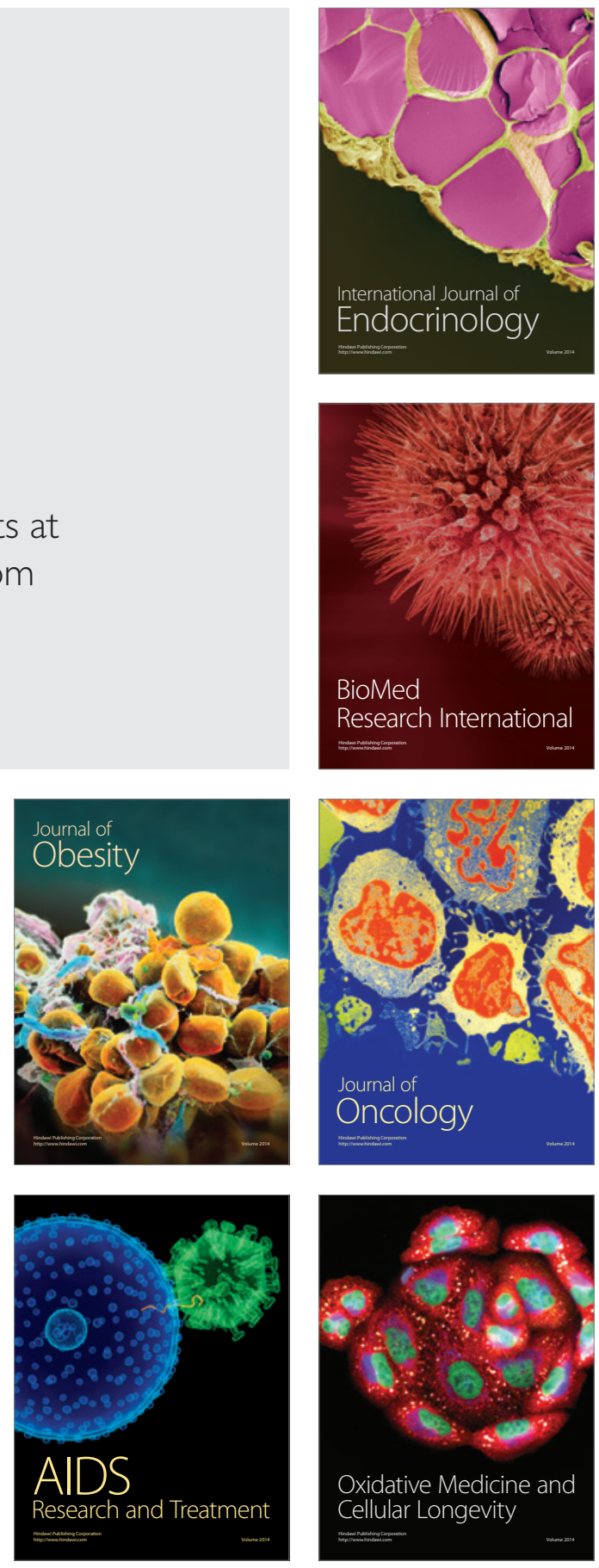